\title{
Finding 'a safe place to cry': A review of research and evidence informing social work with refugees and new settlers in Aotearoa New Zealand
}

\author{
Jenny Pepworth and Mary Nash
}

Jenny Pepworth is currently working as a social worker at Refugee Services in Palmerston North. (jennypepworth@xtra.co.nz). Mary Nash is a Life Member of ANZASW and lectures at Massey University.

\section{Abstract}

This article presents current and relevant research findings relating to settlement in Aotearoa New Zealand for both refugees and migrants. The article looks at how losses experienced through migration impact on settlement outcomes. Protective and risk factors for new migrants' adjustment including family and social support networks, language issues, employment opportunities, discrimination and prejudice as well as the size of different migrant communities are all explored. Social policy which aims to achieve social cohesion must adequately address the needs of both newcomers and host society members.

Social workers need to be aware of the settlement issues faced by their clients at the micro, meso and macro levels in order to competently and ethically meet their clients' needs in this field of practice. The article provides evidence based on research for practice.

\section{Introduction}

The movement of people (voluntary and forced) across borders is an international phenomenon, an expression of globalisation with implications for the economic and political stability of nations and their cultural identity. Aotearoa New Zealand, by virtue of its distance from other land masses and the absence of close border conflicts, is not threatened in the same way as are so many other states by the prospect of unmanageable numbers of asylum seekers and refugees wishing to resettle themselves. At the same time, however, New Zealand's immigration policies - whether characterised as globalising international patterns of inward migration (Bedford, Ho and Lidgard, 2002) or as specifically 'Asianising' these patterns (Parr, 2000) - have resulted in a rapid increase in the numbers of foreign-born residents from diverse cultural and linguistic backgrounds (Nash and Trlin, 2006, p.1). Abbott et al. (2000, p.54) note that:

Migration involves losses, disruption to families and life patterns and exposure to multiple stressors, new experiences and challenges. These are all magnified when...migrants relocate in a very different culture and become members of a visible ethnic minority. 
Migration and settlement have historically been, and remain, integral to the formation of Aotearoa New Zealand society. Aotearoa New Zealand was originally settled by Pacific Island peoples, who comprise the tangata whenua, the indigenous people of Aotearoa. During the 19th century, Britain became the largest source of immigrants. Apart from the Chinese, arriving in the early 20th century, and people of the Pacific Islands, arriving in the 1950s, New Zealand's settlement until the introduction in 1987 of the Immigration Act, had been relatively 'uni-cultural' with the numbers of non-British immigrants being minimal. Changes in New Zealand's immigration laws in the 1980s facilitated the immigration of people from non- traditional source countries and, during the 1990s, increasing numbers of immigrants from Asia, the Middle East, Africa and Eastern Europe arrived in New Zealand (Mortensen, 2008).

With the growth in immigrant diversity, almost one in five New Zealanders are foreign born (Abbott, Wong, Williams, Au and Young, 2000), positive settlement outcomes have become increasingly important for both newcomers and host society members (Spoonley, Peace, Butcher \& O'Neill, 2005). In the New Zealand context this involves the interaction between a bicultural host society and the new concept of multiculturalism (Ngai \& Chu, 2001). Settlement issues for New Zealand, therefore, are relatively unique.

For over a century, until the 1970s, the assimilation of Maori with New Zealanders of European origin had been the prevalent ideology (Bedford, Ho \& Lidgard, 2000). The ideological focus changed to biculturalism during the 1970s and it is not surprising that there is now some concern over how multiculturalism will impact on biculturalism (Spoonley et al., 2005). Practitioners need to be conscious of, and sensitive to, this tension. According to Briggs (2001), biculturalism and multiculturalism are not incompatible and by establishing the Ethnic Affairs Service within the Department of Internal Affairs in 1992, the New Zealand Government has shown some commitment to resolving this new challenge.

Social cohesion has recently been adopted as an appropriate policy response to settlement in New Zealand. The Immigration Settlement Strategy (NZIS, 2004, cited in Spoonley et al., 2005, p.98) has the objective of seeing all groups in New Zealand having 'a sense of belonging, participation, inclusion, recognition and legitimacy'. It is therefore important that settlement policies look at not only issues affecting newcomers, but also at the impact of immigration on host society members and at the relationship between host and immigrant communities. Most importantly, the status of tangata whenua, in relation to their interface with immigrant populations, must be acknowledged (Spoonley et al., 2005).

\section{Definitions}

Each year New Zealand accepts a quota of 750 refugees, referred by the United Nations High Commissioner for Refugees. According to the United Nations 1951 Convention on the Status of Refugees, a refugee is a person who:

Owing to well-founded fear of being persecuted for reasons of race, religion, nationality, membership of a particular social group or political opinion, is outside the country of his nationality and is unable or, owing to such fear, is unwilling to avail himself of the protection of that country (www.unchr.ch). 
A small number of refugees may also qualify for residence under the Family or Partnership categories of the normal immigration policy. Policy requirements for this process are onerous and often impossible for refugee applicants to meet. These refugees may not receive the same support and services provided for the quota refugees.

Asylum seekers, in contrast to immigrants and refugees, are people who enter a country without legal documents, or whose documents expire once they have arrived and who claim refugee status. New Zealand, as a signatory to the 1951 UN Convention Relating to the Status of Refugees, has a responsibility to determine the citizenship status of all asylum seekers.

When using the term 'migrants', we refer to people who have moved voluntarily from one country to another, seeking a better life. These are people for whom there would normally be no legal obstacles preventing their return to where they came from.

\section{Migration and loss}

Migration, whether it is voluntary, for migrants, or involuntary, for refugees and asylum seekers, involves profound loss and stress for families. Although all newcomers to a society will have settlement issues and needs in common, the lack of many aspects of social capital amongst refugees and asylum seekers renders their adjustment particularly difficult and, therefore, requires additional policy and support initiatives (Markovic \& Manderson, 2000).

Losses experienced by migrants and refugees are numerous and include loss of country, way of life, family members and friends, social support systems, social status, culture, religion, and for refugees the loss of trust, in addition to the stress of adjusting to life in a new country (Au 2002; Bhugra 2004). Refugees have often witnessed or experienced torture and brutality leading to a huge fear of authority figures and a loss of trust in others as well as a sense of loss of control over their lives (Waitemata District Health Board and Refugees as Survivors New Zealand, 2007). Migrant families, and in particular refugees, are therefore, often dealing simultaneously with two huge psychological processes: grieving over loss of their homeland as well as mastering settlement (Vong, 2002).

There seems to be little research into the implications of loss of 'physical place' for migrants, particularly refugees, who left their homelands without preparation or possessions, including photographs, and may never be able to return. Markovic and Manderson (2000, p. 321) quote a Croatian refugee, living in Australia, who said 'You have here material things. But I miss that air, people. Maybe we miss our impoliteness too...'. Many recently arrived refugee families to New Zealand have come from warmer climates. Some have found adjusting to the cold, wet winters to be particularly difficult, and the weather, as well as the enclosed landscape (as opposed to open, empty, rugged spaces), compounds feelings of homesickness. Another aspect of losing one's homeland is the confusion over feelings of loyalty to a place and people from which refugees, in particular, have been forced to flee. Candappa (2000, p. 31) quotes a 13-year-old Kurdish boy from Turkey, living in Britain, who says, 'I get sad when people ask me if I am a refugee. I don't want to be a refugee because...I don't want people to think my country is bad'. 
Feelings associated with grief and loss may lead to deteriorating mental health if appropriate support is not available. Abbott et al. (2000), Vong (2002) and Wang (2000) have all investigated the impact of migration stress on mental health and have looked at protective and risk factors for new migrants' adjustment. At the individual level, risk and protective factors include family and other social support networks, English language ability and appropriate employment opportunities. Post-migration variables within the community include societal risk factors such as prejudice and discrimination and protective factors such as size of the migrant community.

\section{Migration and implications for the family}

Family and other social support networks are crucial for mental health and successful settlement. Migration, however, often involves family separations or loss and can also have a profound effect on the structure of families and the roles their members are accustomed to playing (Vong, 2002). The Ministry of Education report (2000, p. 18) states that from a family systems perspective, the loss experienced through settlement may 'disrupt life cycle patterns of interaction, roles, boundaries and inner codes of what is expected of family members'. This report concludes that a significant part of family trauma stems not only from the grief and trauma of losing family members, but also from losing their familiar roles within the family.

The younger generation of migrant and refugee families may be at risk of losing the role of dependent child and becoming responsible for the family's interaction with the host society, due to better linguistic skills. This places inappropriate responsibility on the younger generation, for example when they become privy to confidential information, as well as causing role confusion in families. Although parents may depend on their children for some interaction with the host culture, they resent them assuming this role in all aspects of their lives as this undermines parental authority. Thus young people may be placed in extremely ambivalent situations where, at times they are expected to act as the dominant adult in a family, and at other times as a submissive child (Vong, 2002).

Migration may also result in changing roles for spouses. It may be easier for newcomer women to find suitable employment. The inability of the male breadwinner to fulfill his traditional role may cause additional stress and tension, and increase women's vulnerability to experiencing abuse from spouses. The professional community faces huge challenges in addressing this issue in a socio-culturally sensitive manner. Culturally appropriate support groups and the provision of appropriate information and education is essential if women are to integrate safely and successfully (Ahmad, Riaz, Barata and Stewart, 2004).

It is common for different generations in migrant families to acculturate at different rates. ${ }^{1}$ Chu (2002) notes that parents may fear the 'westernisation' (assimilation and therefore loss of ethnic culture) of children, preferring to see their children adopt a separation-style acculturation strategy. Kim's (2006) study of Korean adolescent adjustment found that those

Berry (1987) has identified four commonly adopted acculturative styles: Integration, where there is strong identification with both ethnic and new cultures; assimilation, where identification is strong with the new culture and weak with the ethnic culture; separation where identification is mainly with the ethnic culture and marginalisation where there is weak identification with both cultures. 
who had been living in New Zealand for longer periods experienced more intergenerational conflict at home because of different acculturation levels. Kim quotes a student saying, 'My dad is not familiar with the western culture so my dad gets really paranoid (of me hanging out with Kiwi friends)' (Kim, 2006, p.212).

\section{School as a support system for young migrants and refugees}

School is the environment in which newcomer youth inevitably come face-to-face with the dominant culture. Although school has the potential to be a good support system, it may be experienced as a stressful environment. Wang (2000) uses the example of an 11-year-old Chinese newcomer who had to eat his lunch in the toilet because he was afraid he would be teased if seen eating rice, rather than sandwiches. Bullying and other discriminatory experiences were frequently reported in Kim's (2006) study, mostly in the initial stages of settlement before the newcomer Korean youth were able to communicate successfully in English. This delegation to the status of 'other' or 'outsider' makes integration particularly difficult and, therefore, having other members of their ethnic group in the same school or community is a significant protective factor. Where this doesn't occur or only occurs on a small scale in smaller schools or towns, it may further disadvantage newcomer youth.

Chu (2002) notes that feelings of homesickness, rejection, depression, anxiety, loneliness and lack of confidence are all common amongst newcomer youth seeking help. Being accepted by peers and allowed to join host society peer groups help positive integration. Wong and Everts (2002) consider that there is a perception by host society members that Chinese students do not want to mix, thus making integration more difficult. The necessity, therefore, of involving both the newcomer and host society members in resettlement programmes is obvious. Integration is not a one-way process. The host society must be ready and open to accepting multiculturalism.

\section{Working at micro, meso and macro levels}

Working at a micro level, social workers must have an understanding of the different cultural backgrounds of their clients. They must be aware of the conflict in acculturation styles some of their clients may be experiencing, and be sensitive to the needs of the family as a whole. Values that encourage independence and assertiveness in students before they and their family are ready for them may place so much stress on the family system that it becomes unable to adequately support its members (Chu, 2002).

Nash (2005) advocates the importance of looking at how different settlement issues must be addressed at not only a micro level, but at the meso and macro as well. At a meso level, schools need to employ bilingual staff (Chu 2002). In some schools, a member of the community from which different groups of refugees have arrived, has been employed by the Ministry of Education as an interpreter and liaison person between school and home. This has had positive results and enabled a good relationship to develop between school and home, quickly eliminating misunderstandings.

At the macro level, the Ministry of Education needs to implement a comprehensive support system for migrant children (Ministry of Education, 2000). Much of the literature highlights the importance of using successfully integrated members of migrant groups as 
support and resource people. Government policies which implement and, most importantly, adequately resource this strategy, will lead to more positive outcomes for youth and their families (Kopala \& Esquivel, 1994).

\section{New settler orientation and social support systems within the community}

On arrival in New Zealand, all quota refugees (but not other migrants) undergo a sixweek induction programme which focuses on their immediate resettlement needs before moving into communities throughout New Zealand (Briggs, 2001). Refugee Services, a national resettlement NGO, is contracted to support the families for six months. Refugee Services operates as an advocacy and support service, using a three-strand model of service delivery, which utilises social workers, cultural workers and trained community volunteers (Refugee Services, 2008). The use of trained volunteers to support families in the community is a unique programme. Having community-based support people provides newcomer families with a diverse range of community contacts which would be impossible to achieve through agency support alone. Apart from the New Zealand Immigration Service (NZIS) and voluntary organisations such as Refugee Services, there is a distinct lack of national services available to meet the longer-term ongoing needs of refugees or migrants (Mortensen 2008). The assumption that skilled migrants are able to successfully settle into New Zealand without access to any specific settlement services has been challenged in various studies sponsored by the NZIS. Those from non-English speaking backgrounds have particular difficulties and in response the NZIS has developed a comprehensive settlement kit for new settlers (Bedford, 2004). The recognition of the need for cultural responsiveness has led to the development of Ethnic Perspectives in Policy from the Office of Ethnic Affairs. This report offers guidelines to policy development, consultation and ethnic responsiveness. There is undoubtedly an acknowledgement and commitment on the part of policy makers to take into account the composition, dynamics and needs of the different ethnic communities in New Zealand. However, to achieve lasting social cohesion, social policies must take cognisance of the fact that different measures are required at different stages of integration and must manage effectively both initial settlement and long-term integration (Mortensen, 2008). Of course, unless social policies are implemented, no matter how good they are on paper, they will not, of themselves, effect change.

Social support systems within the community enhance positive integration experiences and are essential in contributing to social cohesion. Many find it difficult to break into 'kiwi culture' and find substitute support networks. Host society members often keep their distance, leaving newcomers feeling isolated or confined to their own cultural network (Wong \& Everts, 2002). The absence of appropriate social support systems is magnified when newcomers experience discrimination because of their 'visible ethnic minority' status. Recent research undertaken into the experiences faced by new migrants, has found that discrimination, exclusion and prejudice are commonly experienced by newcomers (Butcher, Spoonley $\&$ Trlin, 2006). There are concerns that 'visible minorities' are increasingly facing greater systemic barriers to integration (Mortensen, 2008). Effective settlement policy must therefore address the capacity of the host community to provide access to housing, employment and social interaction. Feelings of loss, in combination with a lack of friendly reception by the host population, are likely to lead to marginalisation, an acculturation style associated with poor mental health outcomes (Ho, 1995). 
Housing policies also impact significantly on social support networks. If newcomers are all housed in the same area, particularly if poverty is also an issue, they may become more visible as an ethnic minority. The capacity of migrant communities to develop dense social relations (separation mode) can be seen to lead to segregation, as much as to social cohesion. The host society may either feel intimidated by the existence of a perceived 'ghetto' or may consider that the group is self supporting and unwilling to be included. In either case, opportunities for integration become scarce. Alternatively, if the community is small and housed over a large area, newcomers will be more prone to social isolation (from their own ethnic groups), but may have more opportunities to integrate with the host society (Spoonley et al., 2005). In smaller centres without 'critical mass' for ethnic communities, social support networks within the ethnic group may be severely limited, leading to social isolation. Social support within refugee communities may also be compromised by historical conflict between different sectors of the community, and in smaller refugee resettlement cities in New Zealand, this tension and conflict may permeate the entire community.

\section{Provision and access to health care services for newcomers}

Poor access to health care services may lead to social exclusion for newcomer groups. Several limitations exist in the delivery of mental health services for migrants. In many cultures there is a stigma associated with mental health and an unwillingness to seek help (Briggs, 2001). Aye and Guerin (2001) consider that the lack of ethnic-specific services in New Zealand might discourage migrant use of available services, as usage increases with the provision of ethnicity-specific programmes. The Wellington Refugees as Survivors (RAS) Centre is one of only two dedicated mental health services for refugees in New Zealand (Chapman, 2002). The service was established and is funded on the presumption that refugees need a trauma treatment service consistent with a DSM IV framework. Chapman, however, questions the relevance of a western-style diagnostic and treatment service in a cross-cultural context. Staff members at RAS have found it imperative that clients be helped first with overwhelming practical needs, such as problems with housing or family re-unification issues, before they can appropriately and successfully engage in counselling. This finding is endorsed by Whelan, Swallow, Peschar \& Dunne (2002) in their Australian research.

As part of its annual resettlement quota of refugees selected by the United Nations High Commission for Refugees, New Zealand accepts refugees with high health needs and disabilities. This situation needs to be reflected in the responsiveness of the health sector to refugee groups (Mortensen, 2008). There is a perception amongst host society members, reinforced by the media, that the health sector is struggling to cope with demand. If social cohesion as a policy response to immigration is to be successful, then this is an area where policy makers must ensure that competition for resources which will damage social cohesion, does not occur.

\section{Clark's ethnographic approach: 'Adopting the stance of learner'}

At the micro level, multicultural work requires more time and resources to meet client expectations. Social work needs to shift from a worker to a client understanding of culture (Russell \& White, 2002). An understanding of the impact of loss, dislocation and trauma on individuals and families is particularly necessary in work with migrant populations (Whelan et al., 2002). Chapman (2002) looks at Clark's (2000) ethnographic approach to understanding and making relevant the cross-cultural social worker/client relationship. 
One of the principles of this approach is 'adopting the stance of learner'. This frees the relationship into becoming a mutual learning experience rather than an expectation that the worker's knowledge is infallible. Nash (2005, cited in Nash et al., 2005, p.148) notes a similar sentiment amongst practitioners. She quotes from one of the survey respondents: 'Teach me about your culture, teach me what I could do that would be helpful ... It is such a respectful, empowering thing to do'.

\section{Clark's ethnographic approach: 'Acknowledging power and socio-political context'}

'Acknowledging power and socio-political context', another principle in Clark's ethnographic approach, is important in the context of working with refugees and migrants. Misuse of power may easily re-traumatise clients. Chapman notes that RAS attempts to prevent this by offering their clients as much choice as possible, including choice over seating arrangements, interpreters and material to be covered. By striving to 'view all interventions through the client-focused lens the agency staff attempt to maintain respect for and empowerment of their clients as primary therapeutic goals. The RAS staff found that basic, compelling needs have to be dealt with before a more in-depth counselling relationship can be established. Whelan et al. (2002) made similar observations in their work with displaced Kosovans accommodated in Tasmania. Although these authors were engaged to provide trauma counselling, their services evolved to community work, which was a more acceptable mode of engaging with their client population.

\section{Clark's ethnographic approach: 'Listening for meaning'}

Another principle of Clark's approach is 'listening for meaning'. Language difficulties may hamper the development of a helping relationship but the use of skilled interpreters can contribute additional cultural information which can enhance the therapeutic relationship.

\section{Clark's ethnographic approach: 'Engaging in self-reflexivity'}

The last of Clark's principles, discussed by Chapman, is 'engaging in self-reflexivity'. This is to ensure that worker/client relationships are not distorted by prejudices and assumptions. Meanings need to be negotiated with clients to ensure that both parties are on the same 'wave-length'.

\section{Language and settlement}

The ability to speak the language of the host country is a fundamental requirement for successful settlement (Ministry of Education, 2000). Difficulties with English language affect access to health care, education and employment, as well as psychological well- being. Being unable to communicate in English will isolate newcomers and add to their loss and sense of 'not belonging' (Guerin \& Guerin, 2002; Ho, Au, Bedford \& Cooper, 2002). Learning a new language however, is often a major source of stress, particularly for refugees who may not be literate in their mother tongue.

As important as the ability to speak English may be for newcomers, the maintenance of their own language is also beneficial. Bilingualism facilitates adaptation and integration into the new society without giving up one's ethnic identity and associated feelings of loss (Potocky-Tripodi, 2002). New Zealand does not have a single strategic approach to language learning for all migrants. The Ministry of Education in New Zealand has well-defined policies to provide funding for schools to teach English as a second language to newcomer youth (Ministry of Education, 2000), but not to teach their mother tongues. 
It was not until 2002 that an adult literacy strategy was developed. As part of the implementation of the Adult ESOL strategy, the provision of bilingual language and literacy tuition was successfully piloted in Somali, Ethiopian and Burmese refugee communities in 2003. The key factors in the success of the trial programmes were that the classes were free; community-based; ethno-specific; owned by ethnic communities; provided transport and childcare; offered inter-generational learning opportunities; addressed settlement needs; and, importantly, prepared students for employment (Ministry of Education, 2004, as cited in Mortensen, 2008).

The New Zealand Government acknowledges that language must not impede access to public services and has established a telephone interpreting service, 'Language Line', to facilitate this (Office of Ethnic Affairs, 2002). Although this is a useful development, agencies may sometimes be unfamiliar or untrained in how to use it, and there are times when it is not appropriate. Professional interpreter services are an essential resource and require interpreters with an adequate awareness and understanding of the cultural backgrounds of different ethnic groups. Bilingual or multilingualism amongst service providers ensures ethical practice and is associated with better outcomes for clients (Wang, 2000). PotockyTripodi (2002) warns, however, that when agencies use cultural workers and interpreters, care needs to be taken to respect different cultural values with regards age, socioeconomic status and religion. In smaller communities in particular, confidentiality is a significant issue. Disclosure of personal information may have been life threatening for refugees and many are suspicious of members of their community from a different tribe or political persuasion. This may have implications for the choice of interpreter (Chapman, 2002). In smaller settlement cities this choice may not be available.

Russell and White (2002) found that migrants at different stages of the acculturation process preferred working with different professionals. Clients who were in a separated mode of acculturation preferred working with practitioners from their own ethnic group, but those who had started integrating or who aspired to an integration acculturation style, were more comfortable working with professionals from the dominant culture. To help compensate for language difficulties, social workers have used art therapy or craft groups to provide a means for clients' emotional expression (Whelan et al, 2002). One immigrant woman told how she used drawing to help her express her sadness as she found art provided her with 'a safe place to cry' (Russell \& White, 2002, p. 643).

\section{Migration and employment}

English language competence for all newcomers is almost always a pre-requisite to finding appropriate employment. However, even once the language barrier is overcome, immigrants may experience reluctance on the part of employers to offer employment opportunities. Previous qualifications and / or work experience are frequently not recognised, resulting in unemployment or under-employment amongst migrants (Bedford, 2004). Unemployment places additional burdens on acculturating families and is not only associated with financial burden, but also loss of self-esteem, depression and restriction of social contact (Ho et al., 2002). The unsatisfactory employment situation in New Zealand, for many newcomer families, has led to the development of the 'astronaut family', amongst mostly, Chinese families. The breadwinner in these families, by continuing to work overseas, maintains her / his status. Although this is seen as a temporary solution for most families, the implications of becoming 
single-parent families and experiencing loneliness and social isolation do not bode well for successful settlement outcomes (Aye \& Guerin, 2001).

At a macro level, it is important that there are appropriate procedures in place for the formal recognition of migrants' skills and qualifications. This leads to better work-related integration, as well as increased confidence in the social institutions of the host society which, in turn, contributes to greater participation and inclusion. Joining the workforce seems to be the most important indicator to the host society of the desire of newcomers to integrate (Spoonley et al., 2005).

Ngai \& Chu (2001) consider the most important intervention at a meso level to be educating employers on strategies to incorporate diversity. They suggest having a dedicated employment service for orientation and job skills training, as well as retraining programmes for those forced to change direction. In the Manawatu, the Ethnic Council has initiated an employment network for migrants which now has its own employment facilitator and has recently hosted a Migrant Job Fair. Some WINZ offices have especially trained staff members to meet the needs of newcomer work seekers. Where WINZ has been able to place case managers on site in Refugee and Migrant Centres, significantly better employment outcomes have occurred (J.R.McKenzie Trust, 2004).

Refugees often experience greater difficulties in entering the work force, as both training opportunities as well as work experience have been disrupted often for as long as 15-20 years following displacement. According to the J.R. McKenzie Trust (2004) there are additional barriers for refugees entering the New Zealand workforce. These include the reluctance of employers to employ refugees for fear of complications around OSH legislation, the cost and difficulty of travelling to some work places and the complications around benefit entitlements and market-related rents. The J.R. McKenzie Trust (2004) has been involved with funding programmes to help refugees into employment. They have found that working at a micro level with work seekers is essential. The participants in these programmes, especially those whose English was poor, needed ongoing support in order to achieve positive outcomes.

\section{Conclusion}

Migrants to New Zealand currently face numerous settlement issues, many of which are different from those faced by previous migrants. It is important that government and nongovernment agencies have relevant policies and service provisions in place, to enhance the settlement experiences of all immigrants arriving from vastly different cultural and linguistic backgrounds (Bedford et al., 2000). Refugees and migrants are minority groups requiring complex and specialised services from social and community workers (Nash, 2005). To remain ethical, social work practice in New Zealand has needed to adapt its relevance to this new client group and has according to Nash, Wong and Trlin (2006) evolved a new field of practice.

Although New Zealand has adopted a notably humanitarian refugee policy and has relatively flexible immigration policies, these are not always matched by adequate central government and public institutional support once migrants arrive. Beyond the provision of initial settlement services there is little provision for the integration of refugee or migrant groups in social policy or public services. Inclusive social policies and practices for the 
long-term social, economic and cultural integration of all migrants are essential to reducing inequalities (Mortensen, 2008). Advocacy at the micro, meso and macro levels, by social workers on behalf of their newcomer client groups, is a core value underlying ethical practice and social workers must keep policy makers informed about the constantly changing needs and issues affecting this group of clients. With innovative policies and adequate resourcing, this new field of practice has the potential to be both challenging and exciting.

\section{References}

Abbott, M.W., Wong, S., Williams, M., Au, M., \& Young, W. (2000). Recent Chinese migrants' health, adjustment to life in New Zealand and primary health care utilization. Journal of Disability and Rehabilitation, 22(1/2), 43-56.

Ahmad, F., Riaz, S., Barata, P., \& Stewart, D. (2004). Patriarchal beliefs and perceptions of abuse among South Asian immigrant women. Violence Against Women, 10(3), 262-282.

Au, P. (2002). Traditional Chinese culture. New Zealand Journal of Counselling, 23(1), 5-9.

Aye, A.M., \& Guerin, B. (2001). Astronaut families: A review of their characteristics, impact on families and implications for practice in New Zealand. New Zealand Journal of Psychology, 30(1), 9-15.

Bedford, R. (2004) The quiet revolution: Transformations to migration policies, flows and outcomes, $1999-2004$. New Zealand Geographer, 60(2), 58-62.

Bedford, R., Ho, H., \& Lidgard, J. (2000). International migration in New Zealand: Context, components and policy. Migration Research Group and Population Studies Centre, Department of Geography, University of Waikato, Hamilton, New Zealand.

Bedford, R., Bedford, C., Ho, E., \& Lidgard, J. (2002). The globalisation of international migration in New Zealand: Contribution to a debate. New Zealand Population Review, 28(1), 69-97.

Berry, J.W. (1987). Acculturation and psychological adaptation among refugees. In D. Miserez (Ed.). Refugees - The trauma of exile. Dordrecht, Germany: Martinus Nijhoff Publishers.

Bhugra, D. (2004). Migration and mental health. Acta Psychiatrica Scandinavica, 109, 243-258.

Briggs, L. (2001). Refugees and migrants: Issues of multiculturalism in Aotearoa New Zealand social work. In M. Connelly (Ed.). New Zealand social work: Contexts and practice (pp. 85-96). Auckland: Oxford University Press.

Butcher, A., Spoonley, P., \& Trlin, T. (2006). Being accepted: The experience of discrimination and social exclusion by immigrants and refugees in New Zealand. New Settlers Programme Occasional Publication No. 13, Palmerston North, New Zealand: Massey University.

Candappa, M. (2000). Building a new life: The role of the school in supporting refugee children. Paper presented at Children 5-16 Final Conference. London.

Chapman, A. (2002). Social work with refugees and migrants. In Truell, R. and Rowland, L., Reflections on current practice in social work (pp. 140-159). Palmerston North, New Zealand: Dunmore Press.

Chu, S. (2002). Adaptation problems of Chinese immigrant students in New Zealand high schools. Journal of Counselling, 23(1), 39-46.

Clark, J. (2000). Beyond empathy: Cross-cultural social work practice. Proceedings of the Joint Conference of the International Federation of Social Workers and the International Association of Schools of Social Work. Montreal: Canada.

Guerin, P., \& Guerin, B. (2002). Relocating refugees in developed countries: The poverty experiences of Somali resettling in New Zealand. In K. Lyon \& C. Voight-Graf (Eds.), 5th International APMRN Conference, Fiji 2002: Selected papers (pp 64-70). Wollongong, Australia: University of Wollongong.

Ho, E.S. (1995). Chinese or New Zealander? New Zealand Population Review, 21(1\&2), 27-49.

Ho, E.S., Au, S., Bedford, C., \& Cooper, J. (2002). Mental health issues for Asians in New Zealand: A literature review. Migration research group, Department of Geography, Hamilton, New Zealand: University of Waikato.

J.R. McKenzie Trust (2004). Supporting refugee resettlement: Refugee employment programme. Wellington: J.R.McKenzie Trust.

Kim, G.H. (2006). Experience of Korean adolescents' adjustment in New Zealand: Things that help and things that impede. In S. Tse, M.E. Hoque, K. Rasanathan, M. Chatterji, R. Wee, S. Garg, \& Y. Ratnasabapathy (Eds.). Prevention, protection and promotion: Proceedings of the second International Asian Health and Wellbeing Conference (pp. 208-216), Auckland: University of Auckland.

Kopala, M., \& Esquivel, G. (1994). Counseling approaches for immigrant children: Facilitating the acculturative process. School Counselor, 4(5), 352-360.

Markovic, M., \& Manderson, L. (2000). Nowhere is as at home: Adjustment strategies of recent immigrant women from the former Yugoslav Republic in southeast Queensland. Journal of Sociology, 36(3), 315-326.

Ministry of Education (2000). Literature review: Interventions for refugee children in New Zealand schools: Models, methods and best practice. Auckland: Auckland UniServices.

Ministry of Education (2004). The adult ESOL strategy: Review of adult refugee education programmes. Wellington: Tertiary Learning Outcomes Policy Unit, Ministry of Education.

Mortensen, A. (2008). Refugees as 'Others': Social and cultural citizenship rights for refugees in New Zealand Health Services. Doctoral Thesis, Massey University, Albany, New Zealand.

Nash, M. (2005). Responding to settlement needs: Migrants and refugees and community development. In M. Nash, 
R. Munford, and K. O’Donoghue (Eds.). Social work theories in action (pp. 140-154). London and Philadelphia: Jessica Kingsley Publishers.

Nash, M., \& Trlin, A. (2006). A survey of non-government/ not for profit agencies and organizations providing social services to immigrants and refugees in New Zealand. Palmerston North: New Settlers Programme, Massey University.

Nash, M., Wong, J., \& Trlin, A. (2006). Civic and social integration: A new field of social work practice with immigrants, refugees and asylum seekers in New Zealand. International Social Work, 49(3), 345-363.

Ngai, M., \& Chu, K. (2001) Issues and service needs of Chinese communities. Social Work Review, XIII(1), 2-6.

Office of Ethnic Affairs. (2002). Ethnic perspectives in policy. A resource (pp. 1-43). Wellington: Office of Ethnic Affairs within the Department of Internal Affairs.

Parr, A. (2000). Immigration and New Zealand: From localism to globalism? New Zealand Sociology, 15(2), 304335.

Potocky-Tripodi, M. (2002). Best practices for social work with refugees and immigrants. New York: Columbia University Press.

Refugee Services Aotearoa New Zealand, 2008. September 2008 Newsletter.

Russell, M., \& White, B. (2002). Social worker and immigrant client experiences in multicultural service provision: Educational implications. Social Work Education, 21(6), 635-650.

Spoonley, P., Peace, R., Butcher, A., \& O’Neill, D. (2005) Social cohesion: A policy and indicator framework for assessing immigrant and host outcomes. Social Policy Journal of New Zealand, (24), 85-110.

United Nations High Commission on Refugees (1951). 1951 Convention relating to the status of refugees. Available online at http:/ / www.unhcr.ch/cgi-bin/ texis/vtx/publ (accessed 16 January 2006).

Vong, C. (2002). The impact of migration on the Chinese family. New Zealand Journal of Counselling, 23(1), 21-24.

Waitemata District Health Board and Refugees as Survivors New Zealand. (2007). Cross-cultural training programme. Auckland: Author.

Wang, J. (2000). Highlighting two gaps in existing New Zealand social services; Settlement programmes and Asian services. Paper presented at the Aotearoa New Zealand Association of Social Workers Biennial Conference Auckland.

Whelan, J., Swallow, M., Peschar, P., \& Dunne, A. (2002). From counseling to community work: Developing a framework for social work practice with displaced persons. Australian Social Work, 55(1), 13-23.

Wong, J., \& Everts, H. (2002). How Chinese migrant couples develop resilience. New Zealand Journal of Counselling, 23(1), 25-32. 